\title{
ENXERTIA RECÍPROCA E AIB COMO FATORES INDUTORES DO ENRAIZAMENTO DE ESTACAS LENHOSAS DOS PORTA-ENXERTOS DE PESSEGUEIRO 'OKINAWA' E UMEZEIRO'
}

\author{
Reciprocal grafting and IBA factors induction on rooting of woody cutting: \\ peach tree 'Okinawa' and japanese apricot tree rootstocks \\ Clecius Spuri de Miranda ${ }^{2}$, Nilton Nagib Jorge Chalfun ${ }^{3}$, Alexandre Hoffmann ${ }^{4}$, \\ Leonardo Ferreira Dutra ${ }^{3}$, Guilherme Vilela de Andrade Coelho ${ }^{2}$
}

\begin{abstract}
RESUMO
O potencial de enraizamento do porta-enxerto pode ser influenciado pelo enxerto e pelo transporte basípeto de auxinas e cofatores. Objetivou-se verificar o efeito do ácido indolbutírico (AIB) e da enxertia recíproca entre dois porta-enxertos de pessegueiro: o umezeiro (A) e o pessegueiro 'Okinawa' (B), nas concentrações de 0 e $4000 \mathrm{mg} . \mathrm{L}^{-1}$, no enraizamento de estacas lenhosas dessas duas espécies. As estacas foram enxertadas nas seguintes combinações enxerto (enxerto com duas gemas e sem folhas)/porta enxerto (20 cm de comprimento): $\mathrm{A} / \mathrm{B}$ e B/A. Como testemunhas, foram utilizadas estacas não enxertadas e tratadas ou não com AIB. Posteriormente, as estacas foram colocadas em sacos de polietileno preto contendo areia lavada e de granulometria média e mantidas em casa-de-vegetação sob nebulização intermitente durante 80 dias. Observou-se que a utilização do AIB aumenta o percentual de enraizamento, o número e o comprimento médio de raízes primárias das estacas de pessegueiro 'Okinawa' e do umezeiro enxertadas ou não. A enxertia recíproca entre o pessegueiro 'Okinawa' (porta-enxerto)/umezeiro (enxerto), quando tratadas com AIB, aumentou o percentual de enraizamento de estacas de pessegueiro 'Okinawa'.
\end{abstract}

Termos para indexação: Prunus persica, Prunus mume, estaquia, fitorregulador.

\begin{abstract}
Rootstock rooting potential may be influenced by the graft because auxin down movement and cofactors. The objective was to verify the reciprocal grafting effects between peach tree rootstock: Japanese apricot (A) and 'Okinawa' (B), IBA at the 0 and $4.000 \mathrm{mg} \mathrm{L}^{-1}$ concentrations upon both woody cutting rooting. The following grafting combinations were used on the grafted cuttings (two gems graft without leaves) in rootstock $20 \mathrm{~cm}$ long: A/B and B/A and woody cuttings not grafted an treated IBA as check. Later the cutting were kept in black polyethylene bags containing washed sand and maintained in greenhouse with intermittent mist during 80 days. IBA was efficient to improve the rooting, percentual, number and length primary roots of peach tree 'Okinawa' and Japanese apricot cuttings grafted or no. The reciprocal grafting between 'Okinawa' peach tree (rootstock)/Japanese apricot (graft), treated IBA, improved the rooting cuttings percentual 'Okinawa' peach tree.
\end{abstract}

Index terms: Prunus persica, Prunus mume, cutting, growth regulator.

(Recebido para publicação em 20 de setembro de 2002 e aprovado em 13 de janeiro de 2003)

\section{INTRODUÇÃO}

O pessegueiro (Prunus percica (L.) Batsch) e o umezeiro (Prunus x mume Sieb \& Zucc) são originários da China e pertencentes à família Rosaceae.

No sul do Brasil, o pessegueiro é propagado exclusivamente por enxertia (FACHINELLO et al., 1982), sendo os porta-enxertos obtidos de caroços provenientes da indústria. Devido a possibilidade de ocorrência da polinização cruzada, ocor- re a segregação genética e perda de caracteres agronômicos desejáveis, a exemplo da tolerância a nematóides do pessegueiro 'Okinawa'. Além disso, proporciona desuniformidade no viveiro e pomar e dificulta um programa de certificação de mudas, o que requer o conhecimento da origem genética da muda, tanto do enxerto, quanto do porta-enxerto.

\footnotetext{
1. Parte da dissertação apresentada à Universidade Federal de Lavras/UFLA - Caixa Postal 37 - 37200-000 - Lavras, MG, pelo primeiro autor, para obtenção do grau de Mestre em Agronomia, Área de concentração Fruticultura. Bolsista CNPq

2. Aluno de Pós-graduação do Departamento de Agricultura da UFLA. clecius@lavras.br

3. Departamento de Agricultura/UFLA. nchalfun@ufla.br

4. Pesquisador, Embrapa/Uva e Vinho - Caixa Postal 130 - 95700-000 - Bento Gonçalves, RS.
} 
O umezeiro vem despertando interesse como porta-enxerto para pessegueiro e nectarineira, devido à sua rusticidade, sanidade, adaptação ao inverno brando, produtividade, bem como às suas características enanizantes, que se transmitem às variedades copas, permitindo um cultivo intenso por meio de adensamento (DALL'ORTO et al., 1995/1998).

Assim, a propagação vegetativa, por proporcionar indivíduos geneticamente idênticos à planta-mãe, constitui uma estratégia fundamental para obtenção de material propagativo homogêneo, assim como fixação das características genéticas desejadas.

Em espécies ou cultivares com diferentes potenciais de enraizamento, a enxertia recíproca (ER), na qual um mesmo genótipo é usado como enxerto em uma combinação e como porta-enxerto em outra, poderia ser uma alternativa para melhorar o enraizamento. Essa técnica utiliza um enxerto, que poderá ser uma cultivar copa ou um outro porta-enxerto, cujos fatores se translocariam para o porta-enxerto e favoreceriam a emissão de raízes.

Hess (1963), trabalhando com Hedera helix e Hibiscus rosa-sinensis, verificou que enquanto uma cultivar de fácil enraizamento possuía, no mínimo, quatro substâncias consideradas promotoras do enraizamento, em outra cultivar de menor percentual de enraizamento, essas substâncias encontravam-se ausentes ou em pequenas quantidades.

Dessa forma, é provável que fatores que estimulem o enraizamento em maiores teores em espécies ou cultivares com maior facilidade de enraizamento sejam transmitidos dentro de um sistema enxerto/portaenxerto, facilitando a formação de raízes adventícias em porta-enxertos de díficil enraizamento (CHALFUN, 1989).

Overbeck e Gregory (1945) constataram que Hibiscus branco era uma espécie de difícil enraizamento, possivelmente pela deficiência de açúcares e substâncias nitrogenadas além da auxina, o que não foi verificado para a cv. vermelha, que possui facilidade de enraizamento. Em contrapartida, quando se enxertaram garfos enfolhados do Hibiscus vermelho sobre o branco, constataram efeito indutor no enraizamento desse último. A cultivar vermelha poderia ter agido como indutora do enraizamento por meio de fatores hormonais ou até nutricionais, necessários ao enraizamento do Hibiscus branco.

Chalfun (1989) verificou uma porcentagem de enraizamento de Hibiscus, das cultivares vermelha e branca de 84,38 e 20,31\%, respectivamente. Quando se enxertaram garfos da cultivar vermelha com presença e com ausência de folhas sobre a cultivar branca (porta- enxerto), obteve-se uma porcentagem de enraizamento de 47,71 e $44,06 \%$, respectivamente.

$\mathrm{O}$ uso de fitorreguladores tem por finalidade induzir o processo rizogênico, aumentar a porcentagem de estacas que formam raízes, o número e qualidade das raízes formadas e a uniformidade no enraizamento. O ácido indolbutírico tem sido a auxina mais utilizada, pois é fotoestável, de ação localizada, persistente, não tóxico em ampla gama de concentrações e não é atacado por ação biológica.

Mayer (2001), em estudos com a propagação do umezeiro por meio de estacas herbáceas, observou que o AIB na concentração de $2.000 \mathrm{mg} \mathrm{L}^{-1}$ proporcionou um enraizamento de $91,88 \%$.

Devido à facilidade da propagação do por meio de estacas, vários trabalhos são realizados com o intuito de viabilizar esse método. No caso do 'Okinawa', os resultados ainda são contraditórios, com porcentagens variando desde 16\% (ANTUNES et al., 1994) até 90$100 \%$ de estacas enraizadas (CHALFUN et al., 1994).

O presente trabalho foi desenvolvido com intuito de verificar o efeito da enxertia recíproca e do AIB sobre o enraizamento adventício de estacas lenhosas de porta-enxerto para pessegueiro.

\section{MATERIAL E MÉTODOS}

Foram utilizadas estacas lenhosas de ramos de ano de pessegueiro 'Okinawa' e umezeiro. As estacas que se constituíram em porta-enxertos foram preparadas com $20 \mathrm{~cm}$ de comprimento e aproximadamente $0,5 \mathrm{~cm}$ de diâmetro, extraídas da porção mediana de ramos do ano, coletadas da parte externa da copa de plantas matrizes com 2 e 4 anos de idade respectivamente, e os enxertos constituiram-se de garfos com 2 gemas e sem folhas. Os tratamentos constituíram-se das combinações enxerto/porta-enxerto entre genótipos de umezeiro e 'Okinawa', quais sejam umezeiro/'Okinawa' e 'Okinawa'/umezeiro. Como testemunha, utilizaram-se estacas lenhosas de pessegueiro 'Okinawa' e umezeiro. A enxertia, realizada previamente, foi feita por meio de garfagem durante o mês de agosto de 2000, com temperatura média de $19,5^{\circ} \mathrm{C}$, e tanto as estacas enxertadas como as nãoenxertadas foram tratadas com AIB nas concentrações de 0 e $4000 \mathrm{mg} \mathrm{L}^{-1}$, tendo a solução como solvente álcool etílico. Foram tratados $5 \mathrm{~cm}$ da extremidade proximal das estacas por um período de tempo de 5 segundos. Os recipientes utilizados foram sacos de polietileno preto com dimensões de 10 × $20 \mathrm{~cm}$ contendo, areia lavada e de granulometria média como substrato. Posteriormente, as estacas foram mantidas em casa-de-vegetação com nebulização 
intermitente e tratadas quinzenalmente com benlate e diazinon para o controle de fungos e pragas.

$\mathrm{O}$ experimento foi conduzido em delineamento inteiramente ao acaso, constituído de 8 tratamentos com 3 repetições de 15 estacas cada uma. Após 80 dias, foram avaliados o percentual de estacas enraizadas, o número médio de raízes primárias e o comprimento médio da maior raiz primária.

\section{RESULTADOS E DISCUSSÃO}

Os maiores percentuais de enraizamento foram obtidos utilizando o 'Okinawa' (enxerto)/umezeiro (porta-enxerto) (Figura 1), o umezeiro (enxerto)/'Okinawa' (porta-enxerto) (Figura 2) com estacas de umezeiro tratadas com AIB na concentração de $4000 \mathrm{mg} \mathrm{L}^{-1}$ (Figura 3). Resultados intermediários foram obtidos com o ' $\mathrm{O}$ kinawa'(enxerto)/umezeiro (porta-enxerto) sem tratamento com AIB e o 'Okinawa' tratado com AIB. Os menores percentuais de enraizamento foram observados em estacas de 'Okinawa', de umezeiro e de umezeiro (enxerto)/ 'Okinawa' (porta-enxerto) não tratadas com AIB (Tabela 1).

O baixo percentual de enraizamento do umezeiro e 'Okinawa' provavelmente ocorre em baixos teores de auxinas endógenas, visto que quando tratados com AIB, há aumento na porcentagem de estacas enraizadas.
Observa-se que estacas de umezeiro quando tratadas apenas com AIB apresenta $62,2 \%$ de enraizamento. Assim, não há a necessidade da realização da enxertia recíproca com o 'Okinawa' visando a enraizar o umezeiro.

A enxertia recíproca de 'Okinawa' (enxerto)/umezeiro (porta-enxerto) proporcionou aumento na porcentagem de enraizamento do umezeiro não tratado com AIB $(28,99 \%)$ e tratado com AIB $(66,67 \%)$ em relação ao umezeiro sem tratamento com esse fitorregulador $(6,67 \%)$. O aumento no percentual de enraizamento do umezeiro enraizado com a enxertia recíproca provavelmente foi devido à interação entre auxinas fornecidas exogenamente (AIB) com cofatores que atuam sinergicamente com as auxinas. Esses fatores são sintetizados em gemas e folhas jovens e, em maior quantidade, em estacas de plantas jovens e são transportados pelo floema a partir do local de síntese (FACHINELLO et al., 1994). De acordo com Hartmann e Kester (1990), há quatro cofatores do enraizamento, os quais não estão todos quimicamente determinados. Sabe-se que o cofator 3 é o ácido isoclorogênico e o cofator 4 consiste de terpenóides oxigenados. Além disso, os fenóis, principalmente o catecol, que atua protegendo a auxina da ação da AIA oxidase, são importantes no processo de enraizamento.

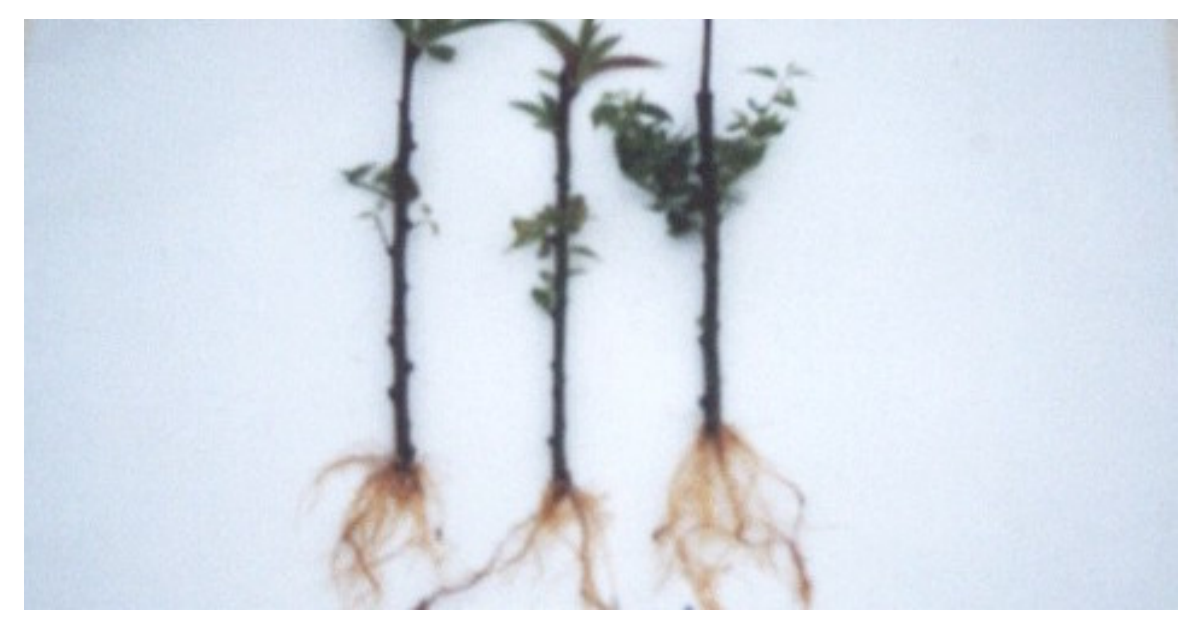

FIGURA 1 - Estacas enraizadas de umezeiro enxertadas com 'Okinawa' e tratadas com AIB. 


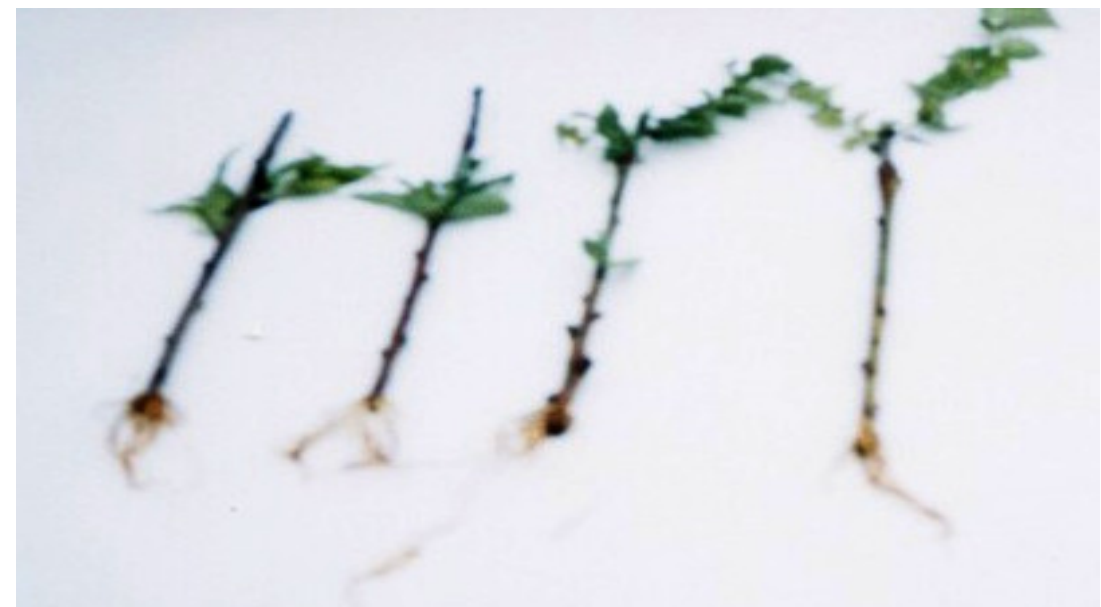

FIGURA 2 - Estacas enraizadas de 'Okinawa' enxertadas com umezeiro e tratadas com AIB.

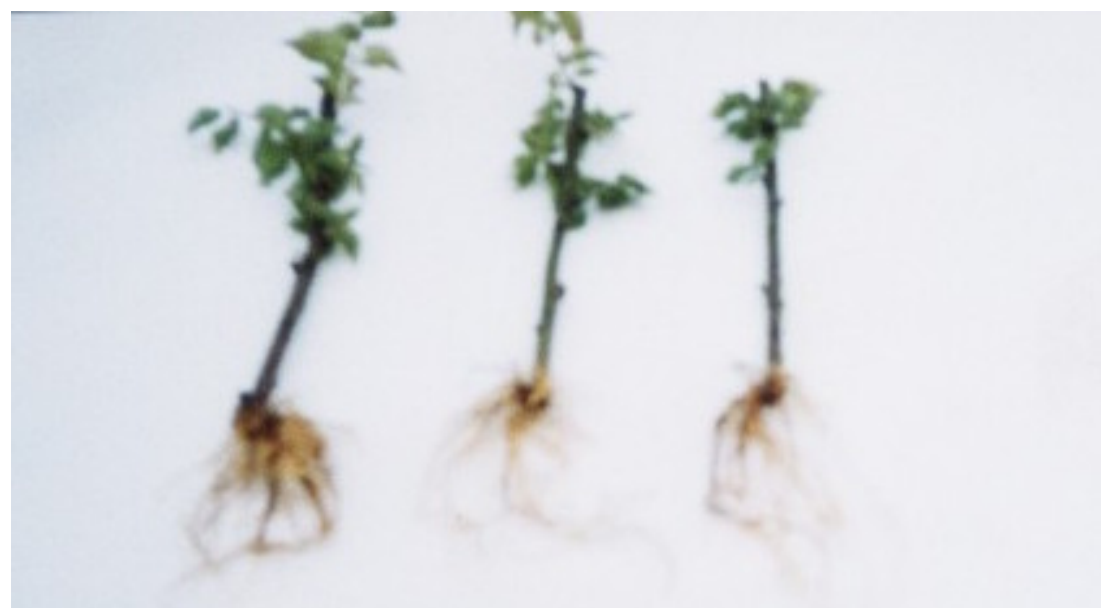

FIGURA 3 - Estacas enraizadas de umezeiro tratadas com AIB.

TABELA 1 - Porcentagem de enraizamento de estacas lenhosas de pessegueiro 'Okinawa' e umezeiro, enxertadas e não enxertadas, tratadas ou não com ácido indolbutírico (AIB). UFLA, Lavras, MG, 2002.

\section{Tratamento}

\section{Enraizamento (\%)}

1. Umezeiro sem imersão em AIB

$6.67 \mathrm{c}$

2. 'Okinawa' sem imersão em AIB

$4,44 \mathrm{c}$

3. Umezeiro com imersão em AIB

4. 'Okinawa' com imersão em AIB

$6,67 \mathrm{c}$

$28,89 \mathrm{~b}$

51,11 a

66,67 a

8. 'Umezeiro (enxerto)/‘Okinawa' (porta-enxerto) com imersão em AIB

Medias seguidas da mesma letra não diferem entre si, a $5 \%$ de probabilidade, pelo teste de Scott e Knott (1974). 
Deve-se ressaltar que, como o material utilizado possuía consistência lenhosa, era esperado que os fatores e cofatores de enraizamento já estivessem presentes quando da coleta das estacas e seriam novamente produzidos quando da cicatrização e emissão de brotações pelo enxerto.

Resultado semelhante foi obtido com a enxertia recíproca de umezeiro (enxerto)/'Okinawa' (portaenxerto). Entretanto, o enraizamento do 'Okinawa' aumentou significativamente quando houve tratamento com AIB $(51,54 \%)$, em relação às estacas tratadas $(13,33 \%)$ e não tratadas $(4,44 \%)$. É provável que nessa cultivar a relação entre auxinas e cofatores do enraizamento seja mais importante na emissão de raízes pelas estacas.

Hess (1963) observa que, além dos fenóis, outras substâncias endógenas interagem com a auxina na formação de raízes. Nesse esquema, quatro cofatores reagiriam com o ácido indolacético (AIA) e existindo um teor de carboidratos e substâncias nitrogenadas em quantidades suficientes, haveria a indução de formação de raízes. No presente trabalho, obtiveram-se resultados semelhantes aos encontrados por Chalfun (1989) em experimentos com enxertia recíproca de Hibiscus, no qual também houve influência do enxerto sobre o porta-enxerto.
Com relação ao número médio de raízes primárias, observa-se que os melhores resultados foram obtidos quando se utiliza o AIB, independente da espécie utilizada como porta-enxerto ou da utilização da enxertia (Tabela 2). Estacas tratadas com essa auxina, além de formarem raízes em suas bases, formaram-se na superfície adjacente, atingida pela imersão auxínica; ao contrário das estacas não tratadas, cuja formação de raízes deu-se apenas na base das estacas, na região do corte. Esse resultado confirma a observação feita por Nachtigal (1999), na obtenção de porta-enxertos de 'Okinawa' e de mudas de pessegueiro, utilizando métodos de propagação vegetativa, em que se verificou que o AIB exerceu um efeito positivo no número médio de raízes formadas, passando de 6,12 raízes sem aplicação para 30,98 com a aplicação desse fitorregulador.

Sharma e Aier (1989) também comprovaram o efeito do AIB no número de raízes de estacas das cultivares de ameixeira 'Santa Rosa', 'Beauty', 'Greegage' e 'Early Transparent Gage', submetidas ao processo de enraizamento no período de verão.

Dutra et al. (2002), estudando o efeito da época de coleta, AIB e triptofano no enraizamento de estacas de pessegueiro, verificaram que, durante o inverno, o número de raízes da cultivar Capdeboscq foi afetado pelo AIB, aumentando até a concentração de $2000 \mathrm{mg} \mathrm{L}^{-1}$

TABELA 2 - Número médio de raízes primárias em estacas lenhosas de pessegueiro 'Okinawa' e umezeiro, enxertadas e não enxertadas, tratadas ou não com ácido indolbutírico (AIB). UFLA, Lavras, MG, 2002.

\begin{tabular}{lc}
\hline \multicolumn{1}{c}{ Tratamento } & Número de raízes \\
\hline 1. Umezeiro sem imersão em AIB & $1,67 \mathrm{~b}$ \\
2. 'Okinawa' sem imersão em AIB & $1,00 \mathrm{~b}$ \\
3. Umezeiro com imersão em AIB & $7,67 \mathrm{a}$ \\
4. 'Okinawa' com imersão em AIB & $10,33 \mathrm{a}$ \\
5. Umezeiro (enxerto)/`Okinawa' (porta-enxerto) sem imersão em AIB & $1,33 \mathrm{~b}$ \\
6. 'Okinawa'(enxerto)/Umezeiro (porta-enxerto) sem imersão em AIB & $3,67 \mathrm{~b}$ \\
7. Umezeiro (enxerto)/`Okinawa' (porta-enxerto) com imersão em AIB & $6,67 \mathrm{a}$ \\
8. 'Okinawa' (enxerto)/Umezeiro (porta-enxerto) com imersão em AIB & $6,00 \mathrm{a}$ \\
\hline
\end{tabular}

Médias seguidas da mesma letra não diferem entre si, a 5\% de probabilidade, pelo teste de Scott e Knott (1974). 
O número médio de raízes primárias é uma variável importante a ser avaliada no processo de propagação por estaquia, pois está relacionada à capacidade de sobrevivência das estacas após a retirada do ambiente de enraizamento. Pode-se utilizar esse dado como indicativo do período adequado de permanência do material sob nebulização intermitente.

Como ocorreu com o número médio de raízes primárias, também o comprimento da maior raiz primária, os maiores valores foram obtidos quando se fez a imersão em AIB, independente da espécie utilizada como porta-enxerto e da enxertia (Tabela 3). Esse incremento no comprimento das raízes pode ser atribuído ao balanço hormonal e/ou a cofatores intrínsecos ao enraizamento favoráveis à formação de raízes mais longas. Esses resultados concordam com as afirmações de Hartmann e Kester (1990), os quais expressam que o AIB estimula as plantas a produzirem raízes maiores, mais fortes e fibrosas.

Rufato e Kersten (2000), estudando o enraizamento de estacas lenhosas de diferentes cultivares de pessegueiro tratadas com AIB e submetidas à estrati- ficação, concluíram que o AIB aumenta o comprimento de raízes para as cultivares Esmeralda e BR2.

Verificou-se uma relação entre o número médio de raízes (Tabela 2) e o comprimento médio da maior raiz primária (Tabela 3). Esse é um aspecto importante, pois não é de interesse prático que uma estaca produza uma única raiz longa ou várias raízes de pequeno comprimento. Portanto, deve-se buscar determinada condição ou tratamento que resulte em um equilíbrio dessas variáveis, ou seja, uma estaca que produza adequado número de raízes com satisfatório comprimento em curto espaço de tempo (MAYER, 2001).

É importante ressaltar que, em função dos resultados obtidos, observou-se um efeito da enxertia recíproca apenas para a porcentagem de estacas enraizadas, não havendo influência no número e comprimento das raízes. Dessa forma, pode-se recomendar a utilização da enxertia recíproca, acompanhada da aplicação de AIB, para obtenção de maior número de estacas enraizadas, cujas raízes formadas apresentam melhor padrão de qualidade.

TABELA 3 - Comprimento médio da maior raiz primária de estacas lenhosas de pessegueiro 'Okinawa' e umezeiro, enxertadas e não enxertadas, tratadas ou não com ácido indolbutírico (AIB). UFLA, Lavras, MG, 2002.

\section{Tratamento}

1. Umezeiro sem imersão em AIB

2. 'Okinawa' sem imersão em AIB

3. Umezeiro com imersão em AIB

4. 'Okinawa' com imersão em AIB

5. Umezeiro (enxerto)/`Okinawa’ (porta-enxerto) sem imersão em AIB

6. 'Okinawa'(enxerto)/Umezeiro (porta-enxerto) sem imersão em AIB

7. Umezeiro (enxerto)/`Okinawa’ (porta-enxerto) com imersão em AIB

8. 'Okinawa' (enxerto)/Umezeiro (porta-enxerto) com imersão em AIB
Comprimento de raízes $(\mathrm{cm})$

$4,00 \mathrm{~b}$

$1,17 \mathrm{~b}$

9,60 a

12,17 a

$4,58 \mathrm{~b}$

$6,02 \mathrm{~b}$

8,67 a

12,66 a

Médias seguidas da mesma letra não diferem entre si, a $5 \%$ de probabilidade, pelo teste de Scott e Knott (1974). 


\section{CONCLUSÕES}

Nas condições em que foi realizado o experimento, pode-se concluir que:

a) A utilização do AIB aumenta o percentual de enraizamento, o número e comprimento médio de raízes primárias das estacas de pessegueiro 'Okinawa' e do umezeiro enxertadas ou não;

b) A enxertia recíproca entre o pessegueiro ' $\mathrm{O}$ kinawa' (porta-enxerto)/umezeiro (enxerto), quando tratadas com AIB, aumentou o percentual de enraizamento de estacas de pessegueiro 'Okinawa'.

\section{REFERÊNCIAS BIBLIOGRÁFICAS}

ANTUNES, L. E. C.; CHALFUN, N. N. J.; RAMOS, J. D.; PASQUAL, M.; CECILIO FILHO, A. B. Propagação vegetativa do pessegueiro 'Okinawa'. In: CONGRESSO BRASILEIRO DE FRUTICULTURA, 13., 1994, Salvador. Anais... Salvador: SBF, 1994. v. 3, p. $877-878$.

CHALFUN, N. N. J. Fatores bioquímicos e biológicos no enraizamento de estacas de Hibiscus rosa sinensis L. 1989. 85 f. Tese (Doutorado em Fitotecnia) - Universidade Federal de Viçosa, Viçosa, 1989.

CHALFUN, N. N. J.; PASQUAL, M.; RAMOS, J. D.; LIMA, P. C.; CHALFUN JÚNIOR, A.; SILVA, T. das G. Efeito do anelamento e diferentes dosagens de ácido indolbutírico na propagação de estacas caulinares do pessegueiro 'Okinawa'. Revista Brasileira de Fruticultura, Cruz das Almas, v. 16, n. 1, p. 119-126, 1994.

DALL'ORTO, F. C.; OJIMA, M.; BARBOSA, W.; MARTINS, F. P.; FOBÉ, L. A. Damasco japonês (umê) em São Paulo: opção para o século 21. O Agronômico, Campinas, v. 47/51, p. 18-21, 1995/1998.

DUTRA, L. F.; KERSTEN, E.; FACHINELLO, J. C. Época de coleta, ácido indolbutírico e triptofano no enraizamento de estacas de pessegueiro. Scientia Agrícola, Piracicaba, v. 59, n. 2, p. 327-333, abr./jun. 2002.

FACHINELLO, J. C.; HOFFMANN, A.; NACHTIGAL, J. C.; KERSTEN, E.; FORTES, G. R. de L. Propagação de plantas frutíferas de clima temperado. Pelotas: Ufpel, 1994. 179 p.
FACHINELLO, J. C.; KERSTEN, E.; MACHADO, A. A. Efeito do ácido indolbutírico no enraizamento de estacas lenhosas de pessegueiro cv. Diamante. Pesquisa Agropecuária Brasileira, Brasília, v. 17, n. 12, p. $247-$ 252, 1982.

HARTManN, H. T.; KeSTER, D. E. Propagacion de plantas: principios practicas. México: Continental, 1990. $760 \mathrm{p}$.

HESS, C. E. Characterization of the cofators extracted from Hedera helix L. and Hibiscus rosa-sinensis L. cuttings. Proceedings of Plant Propagation Society, [S.1.], n. 96, p. 265-268, 1963.

MAYER, A. N. Propagação assexuada do portaenxerto umezeiro (Prunus mume Sieb \& Zucc) por estacas herbáceas. 2001. 109 f. Dissertação (Mestrado em Agronomia) - Universidade Estadual Paulista, Jaboticabal, 2001

NACHTIGAL, J. C. Obtenção de porta-enxertos 'Okinawa' e de mudas de pessegueiro (Prunus persica (L.) Batsch) utilizando métodos de propagação vegetativa. 1999. 165 f. Tese (Doutorado em Agronomia) - Universidade Estadual Paulista, Jaboticabal, 1999.

OVERBECK, J. V.; GREGORY, L. E. A phisilogical separation of two factors necessary for the formation of roots on cuttings. American Journal of Botany, Columbus, v. 32, p. 336-341, 1945.

RUFATO, L.; KERSTEN, E. Enraizamento de estacas de pessegueiro (Prunus persica (L.) Batsch) cvs. Esmeralda e BR2, submetidas à estratificação e ao ácido indolbutírico. Revista Brasileira de Fruticultura, Jaboticabal, v. 22, n. 2, p. 191-194, ago. 2000.

SHARMA, S. D.; AIER, N. B. Seasonal rooting behaviour of cuttings of plum cultivars as influenced by IBA treatments. Scientia Horticulturae, Amsterdan, v. 40, p. 297-303, 1989.

SCOTT, A. J.; KNOTT, M. A cluster analysis method for grouping means in the analysis of variance. Biometrics, Washington, v. 30, p. 507-512, Sept. 1974. 